\title{
Plant Age, Fertilization, and Biological Control Affect Damage Caused by Twospotted Spider Mites on Ivy Geranium: Development of an Action Threshold
}

\author{
George P. Opit \\ Department of Entomology, Kansas State University, 123 West Waters Hall, Manhattan, \\ KS 66506-4004 \\ Yan Chen and Kimberly A. Williams \\ Department of Horticulture, Forestry, and Recreation Resources, Kansas State University, 2021 \\ Throckmorton Plant Sciences Center, Manhattan, KS 66506-5506 \\ James R. Nechols and David C. Margolies \\ Department of Entomology, Kansas State University, 123 West Waters Hall, Manhattan, \\ KS 66506-4004
}

\begin{abstract}
ADDITIONAL INDEX WORDS. integrated pest management, integrated crop management, bedding plants, nitrogen, phosphorus, Phytoseiulus persimilis, Tetranychus urticae, Pelargonium peltatum, biological control, predator : prey ratio

ABSTRACT. In three experiments, damage caused by twospotted spider mite (TSSM; Tetranychus urticae Koch) was correlated with the quality of ivy geranium [Pelargonium peltatum (L.) L'Her ex Aiton], and the action threshold for TSSM on ivy geranium was developed. Ivy geranium quality was measured as overall plant quality - plant size and form, and leaf greenness and glossiness - leaf browning, and leaf distortion. Young plants with high initial TSSM numbers (30 TSSM/plant) exhibited the greatest damage, suggesting that monitoring for TSSM early in the plant production cycle is necessary to prevent extensive damage. The leaf distortion index and overall plant quality were correlated with cumulative TSSM density and marketability in 4-week-old plants infested with 30 TSSM, whereas leaf browning was not correlated with either. Thus, either leaf distortion or overall plant quality can be used to measure economic damage resulting from TSSM. The action threshold for TSSM on ivy geranium was determined using overall plant quality. When the predatory mite, Phytoseiulus persimilis Athias-Henriot, is used to control TSSM, the action threshold was found to be 2 TSSM/leaf. Results also showed that fertilizer combinations of 8 or 24 mM nitrogen and $0.32,0.64$, or $1.28 \mathrm{~mm}$ phosphorus had no effect on cumulative TSSM density. When P. persimilis was released at predator : prey ratios of 1:60, 1:20, and 1:4, TSSM damage, measured as both leaf distortion and overall plant quality, was significantly reduced at 1:4 and 1:20, but not at 1:60. A 1:4 rate resulted in the most marketable plants. These results suggest that $P$. persimilis should be released at a rate of 1:4 when the TSSM action threshold is reached.
\end{abstract}

Annual production of ivy geraniums in hanging baskets is an important component of the lucrative spring bedding plant market in the United States with wholesale sales exceeding $\$ 20$ million in 2001 (National Agricultural Statistics Service, 2004). Twospotted spider mite (TSSM; Acari: Tetranychidae) is a generalist herbivore that is considered a serious pest of ivy geraniums (Smitely, 1993; van de Vrie et al., 1972). The major visible symptoms of foliar damage reported from TSSM feeding include brown dotting in pockets around infested areas, necrotic leaf margins, and complete leaf bronzing (Smitely, 1993). Other

Received for publication 3 Feb. 2004. Accepted for publication 13 June 2004 This project was funded by USDA North Central Region Integrated Pest Management Grant no. 58-5430-8-131 and USDA National Research Initiative Biologically-Based Pest Management Program Award no. 2002-34381-12146. This manuscript has been assigned Contribution no. 04-174-J from the Kansas Agricultural Experiment Station (KAES). We thank the following individuals, all from Kansas State University, for their assistance: Xiaoli Wu and Fengyou Jia for helping with mite inoculations and counts, Paul I. Nelson and James Higgins for statistical advice, and Marci Spaw and Sara Schumacher for providing support in rating ivy geranium plants for twospotted spider mite damage. We gratefully acknowledge Fischer USA, Inc., Boulder, Colo., for providing the plant material used in these experiments. The use of trade names in this publication does not imply endorsement by the KAES of products named nor criticism of similar ones not mentioned. visible symptoms are foliar distortion, dwarfing, folding, and blistering (Nelson, 1998; Tomczyk and Kropczynska, 1985). In addition, infestations of TSSM on ivy geranium impact overall plant appearance by reducing plant size, leaf greenness, and leaf glossiness (G.P. Opit, personal observation).

Since visible foliar damage shows up quickly on many ornamental plants, the number of TSSM found on a leaf can be readily associated with the level of damage observed. This approach has been used to establish the maximum amount of TSSM leaf injury that is tolerable without loss of aesthetic or marketable value (Hamlen, 1978; Hamlen and Lindquist, 1981). However, perhaps because of the thick leaf cuticle (Holcomb and O'Donovan, 1993), visible feeding damage on ivy geraniums is delayed. Therefore, damage levels cannot be directly related to the number of TSSM found on a leaf at any one point in time. For this reason, it is more logical to relate foliar damage on ivy geraniums with cumulative densities of TSSM (i.e., the sum of densities measured on successive sample dates). The cumulative density of TSSM on ivy geraniums is best estimated by periodically counting the number of mites on the youngest, fully-expanded leaves that comprise the sampling units (Opit et al., 2003).

The relationship between TSSM density and visible ivy geranium damage is critical to determination of the economic 
injury level by cost-benefit analysis (Higley and Pedigo, 1996). To determine this relationship for ivy geraniums, the visible symptoms best correlated with cumulative TSSM density need to be identified. Therefore, a primary objective of this research was to determine how three independent measures of visible TSSM damage - leaf browning, leaf distortion, and an overall assessment of plant quality - were correlated with cumulative TSSM density and marketability of ivy geranium plants. Additional objectives were to 1 ) investigate the relationships between the initial number of TSSM at inoculation, plant age, and visible damage; 2) determine the effects of nitrogen (N) and phosphorus (P) on cumulative TSSM density; 3) assess the usefulness of visible TSSM damage indicators in evaluating the effectiveness of various release rates of the predatory mite, Phytoseiulus persimilis (Acari: Phytoseidae); and 4) develop an action threshold for TSSM on ivy geranium for use by commercial greenhouse operators in integrated pest management programs.

\section{Materials and Methods}

GENERAL PROCEDURES. Three experiments were conducted in $7.6 \times 7.6-\mathrm{m}$ glass greenhouses at Kansas State Univ., Manhattan. Ivy geranium 'Amethyst 96' (Fischer, Inc., Boulder, Colo.) was selected because of its susceptibility to TSSM (Opit et al., 2002) and the visibility of damage symptoms on this cultivar. Cuttings were rooted in Oasis strips (Kent, Ohio) and potted in Premier Pro-Mix BX peat-based root medium (Premier-Canada, Dorval, Que.). About $460 \mu \mathrm{mol} \cdot \mathrm{m}^{-2} \cdot \mathrm{s}^{-1}$ supplemental irradiance from high-pressure sodium lamps (Sunlight Supply, Vancouver, Wash.) was provided. Temperature and relative humidity were recorded at three locations in each greenhouse every 30 min using HOBO data loggers (Onset Computer Corp., Bourne, Maine). Four experimental plants selected at representative locations in each greenhouse were weighed daily to determine the need for irrigation. All plants were irrigated using a fertilizer solution when the weight of at least two potted plants dropped by $30 \%$ of the weight at container capacity. This procedure resulted in irrigating about every $2 \mathrm{~d}$ and is consistent with the range of irrigation frequencies shown to produce commercially marketable ivy geranium plants (Jonas, 2000). Fertilizer solutions were consistently applied so that leaching fraction was maintained between $5 \%$ and $15 \%$. Rows of pots were arranged on benches parallel to the cooling pads so that blocking accounted for the temperature gradient in the greenhouse.

Plants were inoculated with TSSM obtained from a large laboratory colony maintained on lima beans (Phaseolus lunatus L.) at Kansas State Univ. The required number of TSSM was transferred from the colony to a $1.5-\mathrm{cm}$-diameter bean leaf disk that was then placed onto one leaf of an experimental plant. To minimize possible movement of TSSM among plants, each pot was placed on an inverted 3.8-L blow-molded container that sat in a pool of water held in a 25 -cm clear plastic saucer, thus creating a "moat." Voucher specimens of TSSM were deposited in the Kansas State Univ. Museum of Entomological and Prairie Arthropod Research under lot number 135. All statistical procedures were accomplished using SAS software (SAS Institute, 2000).

Experiment 1. Plant age and initial tSSM number. The experiment was conducted in a single greenhouse from 5 Nov. 2001 to 15 Jan. 2002. Temperatures inside the greenhouse ranged from 15.2 to $30.3{ }^{\circ} \mathrm{C}$ during the experiment, with a daily average of $20.8 \pm \mathrm{SD}$ of $3.5^{\circ} \mathrm{C}$. Relative humidity ranged from $23.0 \%$ to
$61.4 \%$, with a daily average of $28.2 \pm$ SD of $5.4 \%$. Supplemental lighting was provided from 0600 to $2200 \mathrm{HR}$ resulting in a 16-h photoperiod. Cuttings for the older and younger plants were potted on 5 Nov. and 3 Dec. 2001, respectively, using 13.75-cm-diameter green plastic pots. Fifty cuttings of each age class were potted, one cutting per pot, and fertilized with $1.28 \mathrm{~mm} \mathrm{P}$ and $16 \mathrm{~mm} \mathrm{~N}$. On 17 Dec. 2001, when the plants were 2 and 6 weeks old, 21 plants of each age class were selected based on uniformity of foliage canopy size and leaf color. These plants were divided into three groups of seven plants each; each plant in each group was inoculated with 30,15 , or no (control) adult female TSSM.

Four weeks after inoculation, each plant was assessed for the amount of distortion appearing on young leaves (terminal leaves that were tender and partly unfurled) using a three-point scale. Leaf distortion was categorized according to the extent of puckering and structural deformity. Each young leaf was assigned a rating of 1, 2, or 3 corresponding to slight, moderate, or severe distortion, respectively (Fig. 1). Total distortion was calculated for each plant by adding together the scores of individual leaves. A distortion index for each plant was then calculated by dividing total distortion by the number of shoots on the plant-the size and fullness of the foliage canopy, and by implication the number of leaves, are directly proportional to the number of shoots. The resulting distortion index reflected how visually obvious the leaf distortion appeared on the plant. For example, if both a small and a large plant have the same total distortion score, distortion will be more apparent on the smaller plant because it has less foliage.

The treatment structure for this experiment was a $2 \times 3$ factorial design with pots spaced $50 \times 100 \mathrm{~cm}$ apart. The experimental design was a randomized complete block with six treatments and seven replications (blocks). The experiment was terminated 4 weeks after mite inoculation. To test for effects of plant age and inoculation rate on TSSM damage, an analysis of variance (ANOVA) was performed using PROC GLM. The MEANS statement was used to compute means for each effect.

EXPERIMENT 2: Fertilization AND CUMUlative TSSM DENSITY. This experiment was conducted in two adjacent greenhouses from 5 Oct. to 12 Dec. 2001. In both greenhouses day and night temperatures were set at 24 and $18.5^{\circ} \mathrm{C}$, respectively. However, in "greenhouse 1" actual temperatures ranged from 12.1 to 36.6 ${ }^{\circ} \mathrm{C}$, with an average daily temperature of $20.4 \pm \mathrm{SD}$ of $3.9^{\circ} \mathrm{C}$; and in "greenhouse 2 " temperatures ranged from 16.0 to $38.8^{\circ} \mathrm{C}$, with an average daily temperature of $22.1 \pm 3.9^{\circ} \mathrm{C}$. In greenhouse 1 , the relative humidity ranged from $22.7 \%$ to $85.9 \%$, with an average of $43.9 \pm$ SD of $16.2 \%$; in greenhouse 2 , from $22.4 \%$ to $82.4 \%$, with an average of $42.2 \% \pm 15.8 \%$. Supplemental light in both greenhouses was provided from 0800 to $2400 \mathrm{HR}$, resulting in a photoperiod of 16:8 (light: dark).

The treatment structure was a $2 \times 3 \times 2 \times 2$ factorial with $\mathrm{N}$, P, greenhouse, and initial TSSM number, respectively, as treatment factors. The six fertilizer treatments consisted of two nitrogen rates ( 8 or $24 \mathrm{~mm}$ ) by three phosphorus rates $(0.32,0.64$, or $1.28 \mathrm{~mm}$ ). The experimental design was a replicated randomized complete block with eight replications per treatment. Each plant was inoculated with 30 TSSM 4 weeks after potting and, once per week thereafter, all mite life stages (except eggs) were counted on all youngest, fully-expanded leaves of each plant using a $10 \times$ hand-held magnifying lens. During weekly TSSM counts, leaves were not removed from plants (i.e., nondestructive sampling was done). The youngest, fully-expanded leaf is the sampling unit for estimating TSSM levels on 'Amethyst 96' 
ivy geranium and a strong relationship exists between the mean number of TSSM on youngest, fully-expanded leaves and the total number of TSSM on a plant (Opit et al., 2003). The number of all mite life stages (except eggs) on each plant was determined by destructive sampling 8 weeks after the plants were potted (4 weeks after inoculation with TSSM).

The cumulative TSSM density for each plant was computed by summing TSSM densities on youngest, fully-expanded leaves for successive weeks. For example, if the TSSM densities/leaf found during weeks 1, 2, 3, and 4 after inoculation were 3.1, 5.6, 11.7 , and 20.9, respectively, then the cumulative TSSM density would be $41.3 \mathrm{TSSM} /$ leaf.

At the end of the experiment, distortion, browning, overall plant quality, and marketability of each plant were determined. The distortion index was calculated as described for Expt. 1. Each leaf that exhibited browning was assigned a rating on a four-point scale: $1,2,3$, or 4 according to whether the brown area was restricted to the leaf margin, $5 \%$ to $30 \%, 30 \%$ to $80 \%$, or $>80 \%$ of the leaf area, respectively (Fig. 2). After examining all leaves on each plant, total browning was calculated for the entire plant by adding together the scores from individual leaves. A browning index for each plant was then calculated by dividing the total browning score by the number of shoots on the plant. The resulting browning index reflects how noticeable browning is on the plant. A plant with many shoots and a high total browning index appears in better condition than one with a similar level of browning, but fewer shoots.

Overall quality of each plant was assessed by taking into consideration plant size and form, and leaf greenness and glossiness, using a 10-point scale. Plants meeting commercial standards would score between six and 10. Plants were also classified into one of three market categories: "premium" plants (highest market value, rating = 3), "discounted" (marketable at a lower price, rating =2), and "unmarketable" (rating =1). Plants with overall plant quality ratings of <6, 6-7.5, and 8-10 were categorized as unmarketable, discounted, or premium, respectively. It is important to note that a plant was assigned to a given marketability category based on its overall plant quality score.

To establish whether browning, distortion, and overall plant quality at harvest were correlated with cumulative TSSM density and marketability, a partial correlation analysis was performed using PROC GLM. The partial correlation analysis was used to control for effects of greenhouse, N, and P. PROC GLM was used to test the effects of treatment factors on cumulative TSSM density and the MEANS statement was used to compute means for each effect (SAS Institute, 2000). The model for data analysis included the effects of greenhouse, block nested within greenhouse, initial TSSM number, N, P, initial TSSM number $\times \mathrm{P}$, initial TSSM number $\times \mathrm{N}$, $\mathrm{N} \times \mathrm{P}$, and initial TSSM number $\times \mathrm{N} \times \mathrm{P}$. severe (far right), respectively.
Experiment 3: Predator : Prey Ratios. This experiment was conducted from 2 Feb. to $25 \mathrm{Apr}$. 2002. Greenhouse temperatures ranged from 16 to $51^{\circ} \mathrm{C}$, with a daily average of $24 \pm$ SD of $4.8^{\circ} \mathrm{C}$. Relative humidity ranged from $20 \%$ to $89 \%$, with a daily average of $43 \pm$ SD of $14.7 \%$. Supplemental lighting was provided from 0600 to $2200 \mathrm{HR}$ resulting in a 16-h photoperiod. Cuttings were planted in 13.75-cm-diameter green plastic pots, one cutting per pot. Rates of $\mathrm{P}$ and $\mathrm{N}$ used were 1.28 and $16 \mathrm{~mm}$, respectively. Plants were then placed in water moats (as described above) on clear plastic sheets made from $60 \times 120$-cm garbage bags that were laid over the greenhouse benches. A 2.5-cm-wide strip of Tanglefoot (The Tanglefoot Co., Grand Rapids, Mich.) was then applied as a barrier around each moat to prevent any inter-plant movement by the agile $P$. persimilis.

TSSM infestation of plants occurred by inoculating each with either 30 or 50 adult females 4 weeks after potting. The number of TSSM/plant was estimated 2 weeks after inoculation (Opit, 2003; Opit et al., 2004). Plants were divided into two groups of 28, one group with 50-170 TSSM/plant and the other with 200-400/plant. These groups were then further subdivided into four groups of seven, three receiving inoculations of the predatory mite P. persimilis released at predator : prey ratios corresponding to 1:60, $1: 20$, and $1: 4$, and the fourth receiving no predators. Releasing $P$. persimilis based on the estimated number of TSSM on each plant means that a desired ratio is maintained in the group of plants assigned to that particular ratio. Voucher specimens of $P$. persimilis were deposited in the Kansas State Univ. Museum of Entomological and Prairie Arthropod Research under lot number 154. Treatment structure was a $2 \times 4$ factorial with seven mite-free control plants. The resulting experimental design was a randomized complete block with nine treatments and seven replications per treatment. Pot spacing was $50 \times 100 \mathrm{~cm}$. The experiment was terminated 6 weeks after TSSM inoculation (i.e., 4 weeks after predator release).

Response variables measured were browning, distortion, overall plant quality, and marketability, which were correlated with cumulative TSSM density using PROC CORR. To test ef-

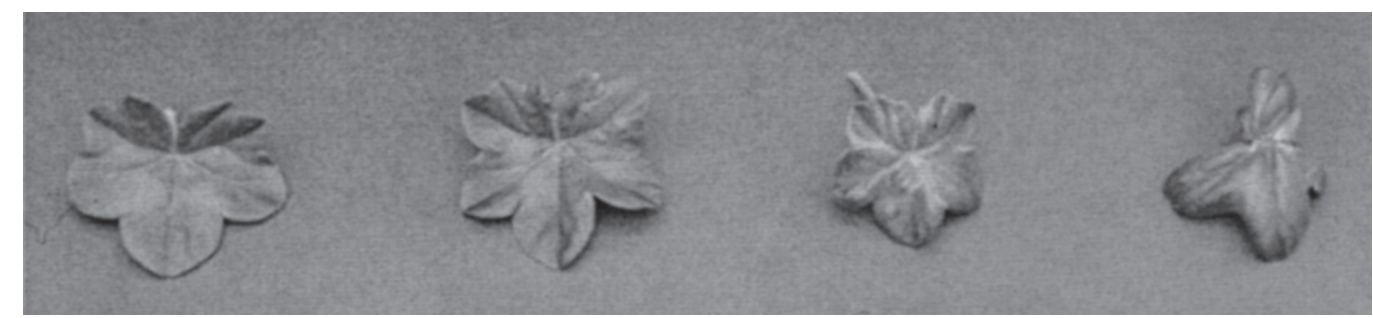

Fig. 1. Levels of leaf distortion resulting from twospotted spider mite feeding damage on ivy geranium are represented. A leaf was undamaged (far left), or assigned a rating of 1, 2, or 3 according to whether distortion was slight, moderate, or

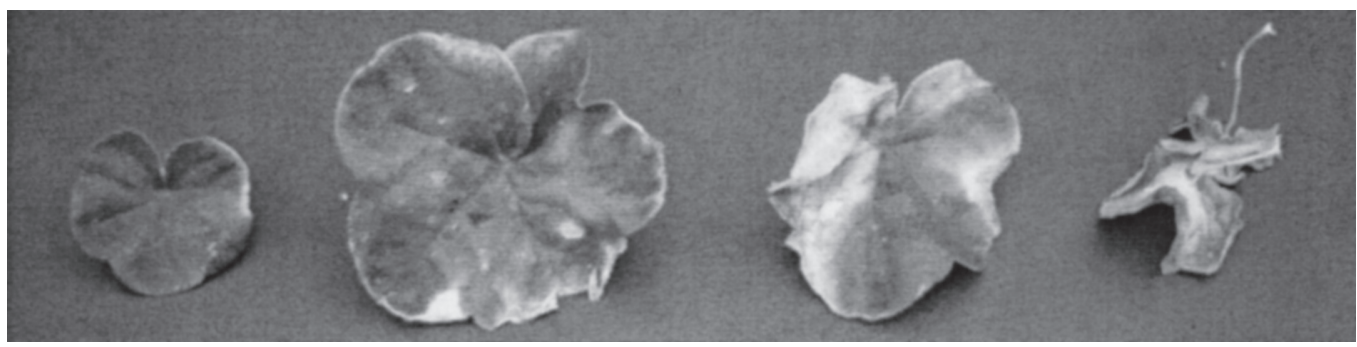

Fig. 2. Levels of leaf browning on ivy geranium infested with twospotted spider mites. A leaf was assigned a rating of 1 (far left), 2, 3, or 4 (far right) according to whether the brown area was restricted to the margin, $5 \%$ to $30 \%$ of total leaf surface, $31 \%$ to $60 \%$, or $>80 \%$, respectively. In this grayscale photo, light areas indicate areas of leaf browning. 
fects of treatment factors on measures of visible TSSM damage, ANOVA analyses were performed using PROC GLM and the MEANS statement was used to compute means for each effect (SAS Institute, 2000).

ACTION THRESHOLDS FOR TSSM ON IVY GERANIUM. To calculate action thresholds for TSSM on ivy geranium, a regression of overall plant quality against cumulative TSSM density was performed from data generated in Expts. 2 and 3. Overall plant quality was used as the dependent variable because it is based on total plant appearance - the key factor influencing ivy geranium sales. The resulting regression equation was used to estimate a cumulative TSSM density associated with an overall plant quality of eight, which is the point at which plant marketability changes from the premium to the discounted category. This cumulative TSSM density represents the damage threshold - the cumulative TSSM population/leaf that leads to unacceptable damage. It is important to emphasize that the damage threshold is not a TSSM density/leaf found at a single point in time during an infestation but a cumulative TSSM density/leaf (i.e., it is a sum of densities measured on successive sample dates).

The production cycle of ivy geranium lasts $\approx 10$ weeks and TSSM can infest ivy geranium plants at any time during production. Therefore, we estimated the lowest number of TSSM/leaf that, unchecked, could potentially reach the damage threshold for each week of the production cycle, assuming plants were infested by TSSM for the first time during that particular week. The minimum number of TSSM/leaf that could potentially reach the damage threshold was estimated using the equation below (Clark et al., 1978):

$$
\mathrm{N}_{\mathrm{t}}=\mathrm{N}_{\mathrm{o}} \mathrm{e}^{(\mathrm{b}-\mathrm{d}) \mathrm{t}}
$$

where, $\mathrm{N}_{\mathrm{t}}=$ number of TSSM after time $\mathrm{t}, \mathrm{N}_{\mathrm{o}}=$ the number of TSSM at the beginning of the time interval, $b=$ the birth rate during time $\mathrm{t}, \mathrm{d}=$ the death rate during time $\mathrm{t}$, and $\mathrm{e}=2.72$, the base of the Napierian logarithms.

For example, if (b-d) and the damage threshold are known, solving for No in the equation below gives the lowest number of TSSM/leaf that could potentially reach the damage threshold (at week 10) for 7-week-old plants, assuming plants were infested by TSSM for the first time at this age.

$$
\mathrm{N}_{\mathrm{o}}+\mathrm{N}_{\mathrm{o}} \mathrm{e}^{(\mathrm{b}-\mathrm{d}) 1}+\mathrm{N}_{\mathrm{o}} \mathrm{e}^{(\mathrm{b}-\mathrm{d}) 2}+\mathrm{N}_{\mathrm{o}} \mathrm{e}^{(\mathrm{b}-\mathrm{d}) 3}=\text { Damage threshold }
$$

In this study, the parameter (b-d) was assumed to be equal to the growth rate of the TSSM population and was estimated using data from experiment 2. The "population change equation" of Clark et al. (1978) can be re-arranged to give:

$$
\left[\ln \left(\mathrm{N}_{\mathrm{t}}\right)-\ln \left(\mathrm{N}_{\mathrm{o}}\right)\right] / \mathrm{t}=(\mathrm{b}-\mathrm{d})
$$

[given that $\ln (2.72)=1$ ]

In Expt. 2, the initial number of TSSM on each infested plant was 30 and the number present 4 weeks after inoculation was determined by destructive sampling. Using the re-arranged equation of Clark et al. (1978) shown above, the rate of population increase for each of the plants inoculated with TSSM was calculated; the average value computed was considered the rate of TSSM population increase on 'Amethyst 96' ivy geranium.

The equation by Clark et al. (1978) permits estimation of TSSM population growth and can be used in the determination of action thresholds for release of biological control agents, provided that information is available on the cumulative TSSM density that may occur after release of the natural enemies, but before the pest is brought under control by the natural enemies. Based on previous research (Opit, 2003; Opit et al., 2004), an additional accumulation of 8.7 TSSM/leaf could occur following the release of $P$. persimilis.

\section{Results and Discussion}

Plant age ANd initial TSSM number. Leaf distortion was significantly affected by both plant age and inoculation rate such that younger plants exhibited greater TSSM damage than older plants (Table 1). This result suggests that ivy geraniums should be monitored immediately after transplanting to detect TSSM infestations during the period when young plants are most susceptible to injury. According to Storms (1971), TSSM damage may be caused by injection of toxins into plant tissue that are translocated mainly to the meristems of the plant. Younger, smaller plants, or those infested with high numbers of TSSM, may receive higher concentrations of toxins per unit weight of tissue than older, larger plants or plants infested with lower numbers of TSSM. Higher concentrations of toxins could result in greater distortion of young leaves compared to old. Also, depending on the variety, the plant may be able to tolerate higher toxin levels.

Fertilization and CUMUlative TSSM Density. Greenhouse, block within greenhouse, $\mathrm{N}$, and $\mathrm{P}$ had no effect on cumulative TSSM density, but initial TSSM density did(Table 2). Greenhouse had no effect on distortion, browning, overall plant quality, and marketability, whereas these four variables were affected by initial

Table 1. Mean leaf distortion observed on young and old ivy geranium plants that were inoculated with 0,15 , or 30 twospotted spider mites (TSSM; Expt. 1). Plants were evaluated 4 weeks after inoculation.

\begin{tabular}{lc}
\hline \multicolumn{2}{c}{ Distortion index ${ }^{z}$} \\
\hline Age $\times$ initial TSSM number $(\mathrm{n}=7)$ & \\
Youngy & $0.19(0.09)$ \\
0 & $1.38(0.43)$ \\
15 & $3.00(0.59)$ \\
30 & \\
Old $\mathrm{x}$ & $0.00(0.59)$ \\
0 & $0.59(0.14)$ \\
15 & $1.35(0.30)$ \\
30 & \\
Age (n 21$)$ & $1.52(0.35)$ \\
Young & $0.63(0.16)$ \\
Old & \\
Initial TSSM number $(\mathrm{n}=14)$ & $0.07(0.05)$ \\
0 & $0.98(0.24)$ \\
15 & $2.18(0.40)$ \\
30 & $P_{\alpha=0.05}$ \\
Significance & 0.0022 \\
Age & $<0.0001$ \\
Initial TSSM number & 0.0817 \\
Block & 0.0660 \\
Age $\times$ initial TSSM number &
\end{tabular}

zLeaf distortion was categorized according to the extent of puckering and structural deformity. Each young leaf was assigned a rating of 1,2, or 3 corresponding to slight, moderate, or severe distortion, respectively. The distortion index was calculated by dividing total distortion of all young leaves on a plant by the number of shoots.

yPlants inoculated with TSSM 2 weeks after potting.

xPlants inoculated with TSSM 6 weeks after potting. 
Table 2. Mean cumulative twospotted spider mite (TSSM) densities observed on ivy geranium plants following treatment with fertilizer combinations of 8 or $24 \mathrm{~mm}$ nitrogen by $0.32,0.64$, or $1.28 \mathrm{~mm}$ phosphorus (Expt. 2). Plants were inoculated with TSSM 4 weeks after potting and evaluated 4 weeks later.

\begin{tabular}{lc}
\hline & Cumulative TSSM density ${ }^{\mathrm{z}}( \pm \mathrm{SE})$ \\
\hline Nitrogen $\times$ phosphorus $(\mathrm{n}=16)$ & \\
8 & $60.0(9.36)$ \\
0.32 & $57.2(8.29)$ \\
0.64 & $61.1(8.62)$ \\
1.28 & \\
24 & $61.0(8.15)$ \\
0.32 & $61.1(8.13)$ \\
0.64 & $55.0(7.68)$ \\
1.28 & \\
Nitrogen (n = 48) & $29.72(4.95)$ \\
8 & $29.51(4.51)$ \\
24 & \\
Phosphorus (n = 32) & $30.24(6.10)$ \\
0.32 & $29.57(5.71)$ \\
0.64 & $29.04(32.15)$ \\
28.28 & $P_{\alpha=0.05}$ \\
Significance & 0.7108 \\
Greenhouse & 0.1999 \\
Block (greenhouse) & $<0.0001$ \\
Initial TSSM number & 0.9404 \\
Nitrogen $(\mathrm{N})$ & 0.9422 \\
Phosphorus $(\mathrm{P})$ & 0.7643 \\
$\mathrm{~N} \times \mathrm{P}$ & 0.9404 \\
$\mathrm{P} \times$ initial TSSM number & 0.9422 \\
$\mathrm{P} \times \mathrm{N} \times$ initial TSSM TSSM number & 0.7643 \\
\hline Cumber & \\
\hline
\end{tabular}

${ }^{2}$ Cumulative TSSM density is the sum of TSSM densities measured on successive sample dates.

TSSM number, P, but not N (Chen, 2003; Opit, 2003).

Distortion was correlated both with cumulative TSSM density $(\mathrm{df}=91, r=0.262, P=0.0116)$ and marketability $(\mathrm{df}=91, r=$ $-0.298, P=0.004)$. Overall plant quality was also correlated with cumulative TSSM density ( $\mathrm{df}=91, r=-0.361, P=0.0004)$ and with marketability ( $\mathrm{df}=91, r=0.809, P<0.0001)$. However, browning was not correlated with either cumulative TSSM density $(\mathrm{df}=91, r=0.025, P=0.812)$ or marketability $(\mathrm{df}=91, R$ $=0.055, P=0.605$ ).

Both leaf distortion and overall plant quality were correlated with cumulative TSSM density and can be considered good measures of visible TSSM damage. Because leaf distortion and overall plant quality were correlated with marketability, they are potentially useful indices for determining economic injury levels of TSSM. However, because leaf browning was not correlated with cumulative TSSM density and may be related to other physiological responses in ivy geraniums, this symptom is not a good predictor of TSSM damage.

Predator : PRey Ratios. As in Expt. 2, distortion was correlated with both cumulative TSSM density $(\mathrm{N}=63, r=0.255$, $P=0.0434)$ and marketability $(\mathrm{N}=63, r=-0.320, P=0.0106)$. Overall plant quality also was correlated with cumulative TSSM density $(\mathrm{N}=63, r=-0.497, P<0.0001)$ and marketability $(\mathrm{N}=$ $63, r=0.858, P<0.0001$ ), whereas browning was not significantly correlated with either $(P>0.05$ in both cases).

According to Opit et al. (2004), predator release ratios of 1:20 and 1:4 effectively lower TSSM populations. Not surprisingly, these ratios also produce plants with better overall plant quality and marketability (Table 3 ). Predator : prey release ratio significantly affected overall plant quality and marketability, but not browning, whereas initial TSSM density had no significant effect on any of the above except cumulative TSSM density (Table 3). Overall plant quality and marketability for the 1:20 and 1:4 release rates were significantly better than for the no-predator control. Both release ratio and initial TSSM density affected cumulative TSSM density (Table 3 ).

A significant interaction between release ratio and initial TSSM density was found for the distortion index (Table 4). The mean distortion indices for release rates of 1:4 and 1:20 at both TSSM densities were significantly lower than those for the 1:60 release rate and the treatment with no predators (Table 4).

Leaf distortion and overall plant quality are useful indicators for evaluating the level of TSSM biological control achieved with different release rates of $P$. persimilis on ivy geranium. The recommendation made by Opit et al. (2004) to use a release rate of 1:4 was based on the ability of $P$. persimilis to consistently reduce both TSSM damage and mite populations. In the floriculture industry, sales are based on aesthetics, and $P$. persimilis must reduce the amount of visual TSSM damage as well as TSSM numbers. Thus, the present study supports earlier recommendations that growers use a release rate of one predator for every four TSSM to control this pest on TSSM-susceptible cultivars of ivy geranium like 'Amethyst 96'.

ACTION THRESHOLDS FOR TSSM ON IVY GERANIUM. Because P, but not $\mathrm{N}$, affects the appearance of TSSM damage on ivy geranium (Chen, 2003; Opit, 2003), a linear regression of cumulative TSSM density against overall plant quality for each nutrient treatment was performed. Testing the equality of all the regression equations for a one-way treatment structure (Milliken and Johnson, 2002) showed that there was no significant difference among them $(\mathrm{F}=1.06 ; \mathrm{df}=150,144 ; P=0.3627)$ (i.e., a single model can effectively describe data from all the treatments). Data from all treatments were then combined and a linear regression of cumulative TSSM density against overall plant quality resulted in the equation below:

$$
\mathrm{y}=-0.0148 \mathrm{x}+8.27\left(r^{2}=0.304 ; \mathrm{df}=1,157 ; P=0.0001\right)
$$

where $\mathrm{x}=$ cumulative TSSM density and $\mathrm{y}=$ overall plant quality.

Based on the equation above, an overall plant quality of eight corresponds to a cumulative TSSM density of 18.24/leaf. The bootstrap technique was then used to compute 1000 cumulative TSSM densities corresponding to an overall plant quality of eight (Blank et al., 1999). Bootstrapping involves sampling with replacement and is done to simulate sampling from a very large population. Therefore, reliable estimates of mean and confidence interval can be derived using bootstrapping. The mean cumulative TSSM density was found to be $17.86 /$ leaf with a $95 \%$ confidence interval of between 7.8 and 26.84/leaf. Because an overall plant quality rating of eight is the point at which plant marketability changes from premium to discounted, a cumulative TSSM density of 17.86/leaf was inferred to be the damage threshold. Using data from Expt. 2 and the procedure described earlier, the TSSM population growth rate was computed as 0.244 /week.

The lowest density of TSSM that, unchecked, could potentially reach the damage threshold was calculated for each week of the ivy geranium production cycle, assuming plants were infested by TSSM for the first time during that particular week. Under condi- 
Table 3. Mean leaf distortion, overall plant quality, marketability, browning, and cumulative twospotted spider mite (TSSM) density ( \pm SE) observed on ivy geranium plants that had initial TSSM densities of 50-150 or 200-400/plant and were treated with Phytoseiulus persimilis released at predator : prey ratios of 0, 1:60, 1:20, or 1:4 (Expt. 3). Plants were inoculated with TSSM 4 weeks after potting, P. persimilis was released 6 weeks after potting, and evaluation was done 4 weeks later.

\begin{tabular}{|c|c|c|c|c|c|}
\hline & $\begin{array}{l}\text { Distortion } \\
\text { index }^{z}\end{array}$ & $\begin{array}{c}\text { Overall plant } \\
\text { quality }\end{array}$ & Marketabilityx & $\begin{array}{l}\text { Browning } \\
\text { index }^{w}\end{array}$ & $\begin{array}{c}\text { Cumulative TSSM } \\
\text { densityv }^{\text {Con }}\end{array}$ \\
\hline \multicolumn{6}{|l|}{$\begin{array}{l}\text { Initial TSSM } \\
\text { density }(n=28)\end{array}$} \\
\hline $50-150$ & $1.84(0.18)$ & $6.73(0.15)$ & $1.57(0.11)$ & $4.06(0.35)$ & $55.53(7.32)$ \\
\hline $200-400$ & $1.86(0.26)$ & $6.63(0.17)$ & $1.43(0.11)$ & $3.26(0.41)$ & $74.29(6.09)$ \\
\hline \multicolumn{6}{|l|}{ Release ratio $(\mathrm{n}=14)$} \\
\hline 0 & $2.71(0.33)$ & $6.21(0.19)$ & $1.14(0.10)$ & $4.30(0.67)$ & $92.82(12.10)$ \\
\hline $1: 60$ & $2.32(0.31)$ & $6.43(0.18)$ & $1.29(0.13)$ & $3.74(0.48)$ & $75.98(8.85)$ \\
\hline $1: 20$ & $1.29(0.17)$ & $6.89(0.17)$ & $1.64(0.13)$ & $3.41(0.43)$ & $47.26(4.90)$ \\
\hline $1: 4$ & $1.07(0.17)$ & $7.18(0.29)$ & $1.93(0.17)$ & $3.18(0.58)$ & $43.58(5.16)$ \\
\hline \multicolumn{6}{|l|}{ Significance, $P_{\alpha=0.05}$} \\
\hline Block & 0.3134 & 0.3556 & 0.4550 & 0.0009 & $<0.0001$ \\
\hline Initial TSSM density & 0.9339 & 0.6245 & 0.2976 & 0.0760 & 0.0041 \\
\hline Release ratio & $<0.0001$ & 0.0129 & 0.0007 & 0.3128 & $<0.0001$ \\
\hline $\begin{array}{l}\text { Initial TSSM density } \times \\
\text { release ratio }\end{array}$ & 0.0354 & 0.9496 & 0.9057 & 0.0710 & 0.2372 \\
\hline
\end{tabular}

${ }^{2}$ Distortion is calculated by dividing total distortion of all young leaves on a plant by the number of shoots.

yOverall plant quality is based on a scale from 1 to 10 with scores of 8 to 10 representing premium commercial quality; scores were proportional to the overall aesthetic quality of the plant.

xMarketability is based on a scale from 1 to 3, which denotes "premium," "discounted," and "unmarketable" plants, respectively. "Browning is based on a rating of one to four according to whether the brown area was restricted to the leaf margin, $5 \%$ to $30 \%$, $30 \%$ to $80 \%$, or $>80 \%$ of the leaf area, respectively. Browning index is calculated by dividing the total browning by the total number of shoots on a plant.

"Because data shows some heteroscedasticity, a square-root transformation was performed. Results of this alternate analysis are the same as presented.

Table 4. Leaf distortion showing the interaction between initial twospotted spider mite (TSSM) density and release ratio (Expt. 3). Ivy geranium plants had initial TSSM densities of 50-150 or 200-400/plant and were treated with Phytoseiulus persimilis released at predator : prey ratios of $0,1: 60,1: 20$, or 1:4. Plants were inoculated with TSSM 4 weeks after potting, P. persimilis was released 6 weeks after potting, and evaluation was done 4 weeks later.

\begin{tabular}{lc}
\hline & Distortion index $( \pm \mathrm{SE})$ \\
\hline Initial TSSM density $\times$ release ratio $(\mathrm{n}=7)$ & $2.1(0.27)$ \\
$50-150$ & $2.6(0.45)$ \\
0 & $1.5(0.19)$ \\
$1: 60$ & $1.1(0.20)$ \\
$1: 20$ & $3.3(0.52)$ \\
$1: 4$ & $2.0(0.41)$ \\
$200-400$ & $1.1(0.26)$ \\
0 & $1.0(0.30)$ \\
$1: 60$ & $P_{\alpha=0.05}$ \\
$1: 20$ & 0.3134 \\
Significance & 0.9339 \\
Block & $<0.0001$ \\
Initial TSSM density & 0.0354 \\
Release ratio & \\
Initial TSSM density $\times$ release ratio & \\
\hline
\end{tabular}

${ }^{z}$ Each young leaf was assigned a leaf distortion rating of 1,2 , or 3 corresponding to slight, moderate, or severe distortion, respectively. The distortion index was calculated by dividing total distortion of all young leaves on a plant by the number of shoots.

tions of heavy TSSM infestation on ivy geranium, an additional accumulation of 8.7 TSSM/leaf could result following the release of $P$. persimilis at recommended rates (Opit, 2003; Opit et al., 2004). This information was used to calculate action thresholds for TSSM on ivy geranium plants of different ages (Tables 5 and 6). For example, 4-week-old plants with an initial TSSM infestation level of 1.1/leaf - the lowest TSSM density that can grow to reach the damage threshold in 6 weeks - will have 1.39, 1.78,
2.27, 2.90, 3.70, and 4.72 TSSM/leaf in weeks 5, 6, 7, 8, 9, and 10 (assuming a TSSM population growth rate of $0.244 /$ week). Cumulative TSSM densities for weeks 5, 6, 7, 8, 9, and 10 would be $2.49,4.27,6.54,9.44,13.14$, and 17.86 , respectively. A TSSM density corresponding to the largest cumulative density that can be added to 8.7 to give a number equal to or $<17.86$ is the TSSM action threshold for plants that are infested for the first time when they are 4 weeks old (i.e., 2.27 TSSM/leaf is the action threshold 
Table 5. The minimum number of twospotted spider mites (TSSM) per leaf that, unchecked, could potentially reach the damage threshold for each week of the production cycle, assuming plants were infested by TSSM for the first time during that particular week. For plants of a given age that have the minimum initial density of TSSM leading to damage, Phytoseiulus persimilis should be released at or before a plant age when the action threshold is reached.

\begin{tabular}{lcc}
\hline $\begin{array}{l}\text { Plant age at initial } \\
\text { TSSM infestation } \\
\text { (weeks) }\end{array}$ & $\begin{array}{c}\text { Minimum initial no. } \\
\text { of TSSM/leaf } \\
\text { leading to damage }\end{array}$ & $\begin{array}{c}\text { Plant age when } \\
\text { action threshold is } \\
\text { reached (weeks) }\end{array}$ \\
\hline 1 & 0.5 & 7 \\
2 & 0.6 & 7 \\
3 & 0.8 & 7 \\
4 & 1.1 & 7 \\
5 & 1.5 & 8 \\
6 & 2.1 & 8 \\
7 & 3.0 & 8 \\
8 & 4.6 & 8 \\
9 & 7.8 & 9 \\
10 & 17.9 & 10 \\
\hline
\end{tabular}

and it is reached when the plants are 7 weeks old).

Commercial bedding plant growers are either going to monitor their crop for TSSM on a regular basis (weekly) from the start of the growing cycle, or they will wait until TSSM damage appears to begin monitoring. If regular monitoring indicates that, for plants of a specific age, a new TSSM infestation meets or exceeds the minimum number of TSSM/leaf that will lead to economic damage, P. persimilis must be released at or before the plant age when the action threshold is reached (Table 5) to ensure adequate control. On the other hand, if a density of TSSM below the minimum that will lead to economic damage is found, $P$. persimilis could be released when plants are older than the age when the action threshold is reached. Where monitoring commences in response to TSSM damage, such as foliar distortion, dwarfing, folding, and blistering (Nelson, 1998; Tomczyk and Kropczynska, 1985), it is prudent to be conservative and to assume that TSSM infested the crop when plants were 1 week old. Therefore, the minimum number of TSSM/leaf that leads to economic damage for plants infested at week 1 can be used to make decisions regarding predator release (Table 6). For plants infested when 1 week old, the action threshold is $2 \mathrm{TSSM} /$ leaf, which is reached when the plants are 7 weeks old (Tables 5 and 6). For plants that

Table 6. The minimum number of twospotted spider mites (TSSM) per leaf for each week of the production cycle that, if left unchecked, could reach the damage threshold, assuming plants were infested by TSSM for the first time during week 1 but went undetected. The damage threshold is equal to a cumulative TSSM density of $17.9 /$ leaf.

\begin{tabular}{lccc}
\hline $\begin{array}{l}\text { Plant age } \\
\text { (weeks) }\end{array}$ & $\begin{array}{c}\text { Minimum initial no. } \\
\text { of TSSM/leaf } \\
\text { leading to damage }\end{array}$ & $\begin{array}{c}\text { Cumulative } \\
\text { no. of } \\
\text { TSSM/leaf }\end{array}$ & $\begin{array}{c}\text { Plant age when } \\
\text { Phytoseiulus persimilis } \\
\text { should be released (weeks) }\end{array}$ \\
\hline 1 & 0.5 & 0.5 & 7 \\
2 & 0.6 & 1.1 & 7 \\
3 & 0.8 & 1.9 & 7 \\
4 & 1.0 & 2.9 & 7 \\
5 & 1.3 & 4.2 & 7 \\
6 & 1.6 & 5.8 & 7 \\
7 & 2.0 & 7.8 & Do not release P. persimilis \\
8 & 2.6 & 10.4 & Do not release P. persimilis \\
9 & 3.3 & 13.7 & Do not release P. persimilis \\
10 & 4.2 & 17.9 & \\
\hline
\end{tabular}

are 1 to 7 weeks old, if sampling determines that the number of TSSM/leaf is equal to, less than, or greater than the minimum mer of TSSM/per leaf that leads to damage, then the plant 6). For plants that are 8 to 10 weeks old, a TSSM density less than the minimum number of TSSM/leaf that leads to damage mo control action is necessary, whereas a TSSM density equal to or greater than the minimum number of TSSM/per leaf that leads to damage implies that releasing $P$. persimilis may not necessarily prevent economic damage (Table 6).

Therefore, we recommend that ivy geranium plants are monitored for TSSM on a weekly basis using a sampling plan developed by Opit et al. (2003). Because it is unrealistic to expect growers to use several different action thresholds, we recommend that predatory mites be released at a predator : prey ratio of 1:4 when $2 \mathrm{TSSM} /$ leaf are found during monitoring. This generalized action threshold is highly conservative because it assumes that plants always get infested during the first week of the production cycle and is derived from an additional accumulation of $8.7 \mathrm{TSSM} / \mathrm{leaf}$ that could result following the release of $P$. persimilis at recommended rates and under conditions of heavy TSSM infestation.

There are several ways to measure TSSM population pressure; we used cumulative spider mite density because it is related to plant damage (overall plant quality) and can easily be manipulated to develop an action threshold for TSSM that is expressed TSSM per leaf - a parameter that can be used in conjunction (2003) to make that decisions. Sampling in most commercial greenhouses weekly sampling. If a different sampling frequency had been used to derive the damage and action thresholds, it is likely that these thresholds would be different.

In summary, this research demonstrated that young ivy geranium plants need to be monitored early in the production cycle prevent feeding damage to the young plants, which are more ible. In addition, both leaf distortion and overall plant quality were correlated with cumulative TSSM density and marketability, suggesting that these indices can be used as measures of economic damage; however, leaf browning is not correlated to TSSM damage. Using overall plant quality, a TSSM action threshold (2 TSSM/leaf) has been developed that growers can use in scouting programs for management of TSSM on ivy geranium using $P$. persimilis. Finally, while our work demonstrates that it might be possible for $P$. persimilis to control TSSM damage on a greenhouse-grown spring bedding plant crop over a range of initial pest densities when released at the moderately low predator : prey ratio of 1:20, we recommend that $P$. persimilis be released at a ratio of 1:4 in order to consistently produce healthy and marketable plants.

\section{Literature Cited}

Blank, S., C. Seiter, and P. Bruce. 1999. Resampling Stats add-in for Excel: Users guide, version 2.0. Resampling Stats, Arlington, Va.

Chen, Y. 2003. Nitrogen and phosphorus fertilization of ivy geranium (Pelargonium peltatum) and impatiens (Impatiens wallerana) affects population 6). the damage and action thresholds presented here are based on 
levels of twospotted spider mite (Tetranychus urticae) and western flower thrips (Frankliniella occidentalis). PhD Diss., Kansas State Univ., Manhattan.

Clark, L.R., P.W. Geier, R.D. Hughes, and R.F. Morris. 1978. The ecology of insect populations in theory and practice. Chapman and Hall, London.

Hamlen, R.A. 1978. Biological control of spider mites on greenhouse ornamentals using predaceous mites. Proc. Fla. State Hort. Soc. 91:247-249.

Hamlen, R.A. and R.K. Lindquist. 1981. Comparison of two Phytoseiulus species as predators of twospotted spider mites on greenhouse ornamentals. Environ. Entomol. 10:524-527.

Higley, L.G. and L.P. Pedigo. 1996. The EIL concept, p. 9-21. In: L.G. Higley and L.P. Pedigo (eds.). Economic thresholds for integrated pest management. Univ. of Nebraska Press, Lincoln.

Holcomb, E.J. and E.J. O’Donovan. 1993. Ivy geraniums, p. 191-199. In: J.W. White (ed.). Geraniums IV. Ball Publ., Batavia, Ill.

Jonas, V.M. 2000. Optimizing fertilization and water regimes of ivy geranium (Pelargonium peltatum). MS Thesis, Kansas State Univ., Manhattan.

Milliken, G.A. and D.E. Johnson. 2002. Analysis of messy data: Volume III. Analysis of covariance. CRC Press, Boca Raton, Fla.

National Agricultural Statistics Service. 2004. U.S. Dept. of Agr. floriculture crops 2003 summary. Sp Cr 6-1(04)a. USDA, NASS, Washington, D.C.

Nelson, P.V. 1998. Greenhouse operation and management, 5th ed. Prentice-Hall, N.J.

Opit, G.P. 2003. Development of biological control of twospotted spider mite, Tetranychus urticae Koch (Acari: Tetranychidae) on greenhouse ivy geranium, Pelargonium peltatum (L.) L'Herex Ait., using the predatory mite, Phytoseiulus persimilis Athias-Henriot (Acari: Phytoseidae). PhD Diss., Kansas State Univ., Manhattan.

Opit, G.P., V.M. Jonas, K.A. Williams, D.C. Margolies, and J.R. Nechols. 2002. Effects of cultivar and irrigation management on population growth of the twospotted spider mite, Tetranychus urticae, on greenhouse ivy geranium. Expt. Appl. Acarology 25:849-857.

Opit, G.P., D.C. Margolies, and J.R. Nechols. 2003. Within plant distribution of twospotted spider mite, Tetranychus urticae Koch (Acari: Tetranychidae), on ivy geranium: Development of a presence-absence sampling plan. J. Econ. Entomol. 96:482-488.

Opit, G.P., J.R. Nechols, and D.C. Margolies. 2004. Biological control of twospotted spider mite, Tetranychus urticae Koch (Acari: Tetranychidae), using Phytoseiulus persimilis Athias-Henriot (Acari: Phytoseidae) on ivy geranium: Assessment of predator release ratios. Biol. Control 29:445-452.

SAS Institute. 2000. SAS/STAT user's guide, version 8, vol. 3. SAS Inst., Cary, N.C.

Smitely, D. 1993. Two-spotted spider mites, p. 331-336. In: J.W. White (ed.). Geraniums IV. Ball Publ., Batavia, Ill.

Storms, J.J.H. 1971. Some physiological effects of spider mite infestations on bean plants. Neth. J. Plant. Pathol. 77:154-167.

Tomczyk, A. and D. Kropczynska. 1985. Effects on the host plant, p. 317-329. In: W. Helle and M.W. Sabelis (eds.). Spider mites: Their biology, natural enemies and control. Vol. 1A. Elsevier, Amsterdam.

Van de Vrie, M., J.A. McMurtry, and C.B. Huffaker. 1972. Ecology of teranychid mites and their natural enemies: A review. III. Biology, ecology and pest status, and host-plant relations of Tetranychids. Higardia 41:343-432. 